DOI: http://dx.doi.org/10.37253/jad.v2i2.4330

\title{
Analisis Lingkungan Wilayah Kampung Tua Tanjung Uma
}

\author{
1 Jeanny Laurens Pinassang, ${ }^{2}$ Yessy Christanti Silaban, ${ }^{3}$ Rickie Chung, ${ }^{4}$ Susanto. \\ 1, 2, 3,4 Program Studi Arsitektur Universitas Internasional Batam \\ 1rickiecungg@gmail.com
}

Informasi Naskah

Diterima: tgl/bln/thn; Disetujui terbit: tgl/bln/thn; Diterbitkan: tgl/bln/thn; http://journal.uib.ac.id/index.php/jad

\begin{abstract}
ABSTRAK
Kampung tua merupakan perkampungan yang disebut sudah ada sejak dulu, bahkan sebelum kota batam berdiri. Salah satunya itu adalah Kampung Tua Tanjung Uma yang terletak disalah satu tanjung bagian utara pulau batam Kecamatan Lubuk Baja dan juga berhadapan langsung depan perairan Selat Singapura. Kampung Tua Tanjung Uma berpotensi menjadi destinasi halal unggulan dibatam yang dapat berdampak baik bagi perekonomian warga sekitar jika dikelola dengan baik.Maka dari itu, diperlukan identifikasi lingkungan agar dapat dikelola dengan baik. Jenis penelitian yang digunakan adalah penelitian kuantitatif dan hanya berfokus pada indikasiindikasi fisik wilayah Kampung Tua Tanjung Uma. Selanjutnya, peneliti memberikan rekomendasi solusi mengatasi permasalahan berdasarkan Penelitian tersebut.
\end{abstract}

Kata Kunci: Kampung tua, Kampung tua Tanjung Uma, penelitian

\section{ABSTRACT}

The old village is a village that is said to have existed for a long time, even before the city of Batam was founded. One of them is Kampung Tua Tanjung Uma which is located on one of the northern headlands of Batam Island, Lubuk Baja Subdistrict and is also directly opposite the waters of the Singapore Strait. Kampung Tua Tanjung Uma has the potential to become a leading halal destination in batam which can have a good impact on the economy of the surrounding residents if managed properly. Therefore, it is necessary to identify the environment so that it can be managed properly. This type of research is quantitative research and only focuses on the physical indications of the Tanjung Uma Old Village area. Furthermore, the researcher provides recommendations for solutions to overcome problems based on the research.

Keyword: old village, Kampung Tua Tanjung Uma, research 


\section{PENDAHULUAN}

Kampung Tua Tanjung Uma adalah kampung tua yang terdapat di daerah Kota Batam yang berada diantara dua tanjung yang terdiri dari Tanjung Pangkal Leppu dan Tanjung Kubur, oleh karena itu warga asli kampung ini menamai kampungnya dengan kata "Tanjung". Nama Tanjung Uma itu sendiri diambil dari tempat tinggal yang disederhanakan pengucapannya menjadi kata "uma". Kampung ini terletak disalah satu tanjung bagian utara Pulau Batam dan juga terletak di pesisir pantai, pinggiran kota Batam. Sebagian besar pada mata pencaharian masyarakat kampung tua tanjung uma adalah nelayan. Selain itu, dikawasan tanjung juga terdapat rumah-rumah panggung bertiang kayu.

Tujuan penelitian ini adalah untuk mengidentifikasi lingkungan khususnya indikasi-indikasi fisik pada wilayah Kampung Tua Tanjung Uma.

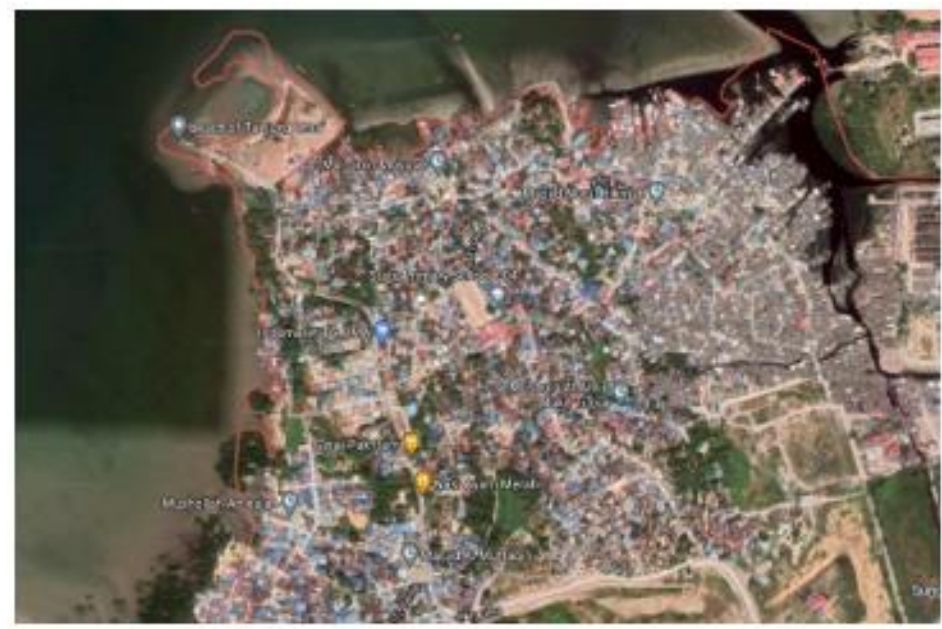

Gambar 1 Kawasan Tanjung Uma

Sumber: https://www.google.com/maps

\section{Kajian Pustaka}

\section{Konsep Desain Generatif}

Suatu bentuk dari permukiman pesisir hadir sebagai refleksi kehadiran ruang yang sangat dipengaruhi oleh eksistensi pantai sebagai sumber dalam mata pencaharian masyarakat. Permukiman pesisir juga dapat diartikan sebagai totalitas lingkungan yang terbentuk oleh 5 unsur, yaitu alam, manusia, masyarakat, ruang kehidupan, serta jaringan untuk memenuhi kebutuhan. Pengertian tersebut dikutip dari Doxiadis (1974). Dalam pengaturan suatu perkampungan kota, permukiman pesisir dibentuk dari suatu sistem kebersamaan ataupun kekeluargaan dalam memanfatkan berbagai ruang sebagai pemenuhan segala aktivitas. Selain itu, pengertian ruang berdasarkan Undang Undang no 24 tahun 1992 terkait penataan ruang, yaitu wujud struktural dan pola pemanfaatan ruang baik yang direncanakan maupun yang menunjukkan adanya hirarki dan keterkaitan pemanfaatan ruang. Dalam penelitian pada kawasan kota, ruang dinyatakan sebagai sesuatu yang memiliki ciri khas atau kekhasan, keunikan tertentu, dan memiliki karakter, (Zahnd, 1999).Dapat disimpulkan bahwa penataan ruang adalah salah satu unsur dalam pembentukan sebuah permukiman pesisir. Ruang menjadi faktor dalam pemanfaatan kawasan atau wilayah secara maksimal. Berdasarkan peninjauan, perkembangan suatu 
kota tidak dapat terelakkan. Perkembangan di kota menjadi masalah terbesar bagi permukiman pesisir, karena resiko yang ditimbulkan sangat cukup tinggi. Salah satunya yaitu, penurunan kualitas pada lingkungan tertentu hingga perubahan sektor di bidang ekonomi. Permasalahan tersebut juga terjadi di wilayah perkampungan Tanjung Uma. Minimnya akses yang didapat, membuat wilayah tersebut kian melemah

\section{Metode Penelitian}

Penelitian ini kami menggunakan metode kuantitatif, yang bersifat deskriptif. Deskriptif berfungsi untuk memaparkan suatu peristiwa, atau kejadian yang sedang berlangsung. Secara lebih rinci penelitian ini akan diarahkan untuk menganalisis masalah karakter secara fisik. Kawasan dalam konteks Kawasan permukiman. Sumber data penelitian ini adalah data primer berupa hasil survey lokasi dan data sekunder berupa peta lokasi. Teknik pengumpulan data pada penelitian ini yaitu menggunakan teknik observasi langsung ke lokasi dan pencarian referensi Pustaka.

Alasan pemilihan lokasi tersebut dikarenakan :

1. Lokasi permukiman tanjung uma merupakan lokasi permukiman lokal yang cenderung bersambungan dengan Kawasan kota.

2. Permukiman tersebut merupakan Kawasan yang kerap ramai saat Ramadhan sehingga dapat dijadikan sebagai salah satu potensi yang berdampak baik bagi perekonomian warga

\section{Hasil dan Pembahasan \\ Karakteristik Fisik Permukiman di kawasan pesisir wilayah Tanjung Uma}

Untuk menganalisis karakteristik fisik permukiman pada kawasan pesisir di wilayah Tanjung Pinggir, dapat dilakukan dengan mengidentifikasi kondisi fisik permukiman berdasarkan tipe jaringan atau prasarana, dan tipe bangunan (Soegiarto,1976).

\section{a. Analisis Prasarana Permukiman Pesisir}

Kondisi prasarana permukiman pada kawasan pesisir di wilayah Tanjung Pinggir dengan melihat beberapa aspek tertentu yang ditentukan berdasarkan standar Keputusan Menteri Permukiman dan Prasarana Wilayah No. 534/KPTS/M/2001 tentang Standar Pelayanan Minimal untuk Permukiman.

\begin{tabular}{|c|l|l|}
\hline No & Prasarana Permukiman & Tanjung Uma \\
\hline 1 & Jalan & $\begin{array}{l}\text { Kondisi jalan tidak cukup } \\
\text { baik karena terlihat sempit } \\
\text { terutama untuk pengguna } \\
\text { kendaraan roda empat }\end{array}$ \\
\hline 2 & Air Minum & $\begin{array}{l}\text { Menggunakan PDAM dan } \\
\text { Air isi Ulang }\end{array}$ \\
\hline 3 & Persampahan & $\begin{array}{l}\text { Sampah di wilayah Tanjung } \\
\text { Uma terlihat bersih }\end{array}$ \\
\hline
\end{tabular}

Berdasarkan kondisi prasarana permukiman pada tabel diatas, dapat disimpulkan bahwa 
di bagian jalan merupakan salah satu prasarana dengan pengelolaan serta pemanfaatan yang tidak baik. Berikut adalah dokumentasi dari prasarana tersebut
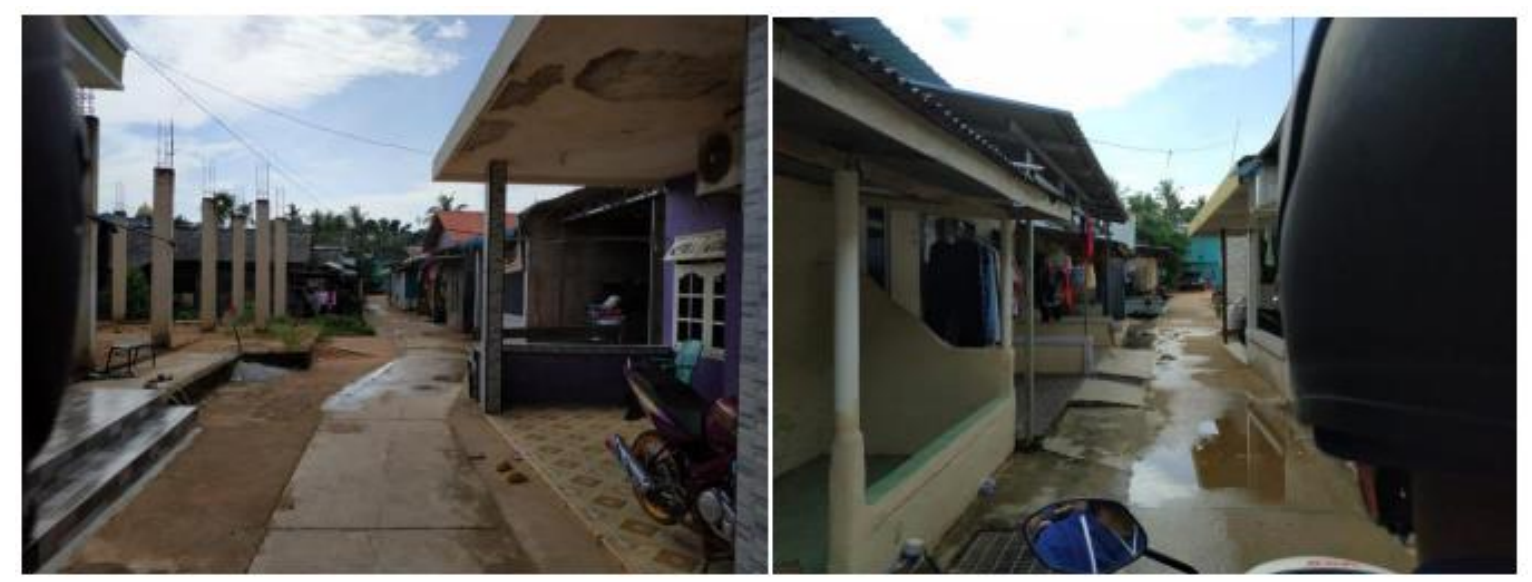

\section{Kesimpulan}

Berdasarkan kesimpulan diatas, maka dapat dikemukakan beberapa saran, diantaranya:

1. Melakukan pengkajian terhadap peraturan yang berlaku dibidang pengelolaan lahan dikota batam.

2. Mempertegas pihak-pihak yang terlibat agar permasalahan dapat segera diatasi

3. Masyarakat dapat melakukan gotong royong agar kebersihan dapat terjaga

\section{Daftar Pustaka}

Zahnd, Markus. 1999. Perancangan Kota Secara Terpadu. Penerbit Kanisius: Yogyakarta.

Soegiarto, A. 1976. Pedoman Umum Pengelolaan Wilayah Pesisir, Jakarta. Lembaga Oseanologi Nasional.

Doxiadis, Constantin A. 1974. Four Red Books: To Help Us Understands What Will Happen to our Human Settlements and What We Are to do Save Them. New York: Oxford University Press. 